Mechanical properties and energy-absorption capabilities of thermoplastic sheet gyroid structures

S. Higuera ${ }^{\mathrm{a}}$, R. Miralbes ${ }^{\mathrm{b} *}$ and D. Ranz ${ }^{\mathrm{a}}$

${ }^{a}$ Department of Design and Manufacturing, University of Zaragoza, Zaragoza, Spain;

${ }^{b}$ Department of Design and Manufacturing, University of Zaragoza, Zaragoza, Spain, DIDYF, C/ María de Luna nº 4, 50018, Zaragoza, Spain, miralbes@unizar.es 


\section{Mechanical properties and energy-absorption capabilities of thermoplastic sheet gyroid structures}

The development of additive manufacturing and lattice structures has created opportunities for the development of lightweight impact-absorption structures that can overcome most constraints of previously used materials such as expanded polystyrene foams. However, for the successful application of such structures, the effects of their variables and performance must be established. In this study, the mechanical properties and energy absorption of thermoplastic sheet gyroid structures were investigated and compared with the performance of current materials. Consequently, the specimens were tested after changing the main variables, i.e., cell size and volume fraction, of various thermoplastic materials such as acrylonitrile butadiene styrene, polylactic acid, thermoplastic polyurethane, and polyamide 12 . Finally, they were tested in a quasi-static compression test and their deformation stages were photographed. The stressstrain curves of all materials changed after adopting the sheet gyroid structure, exhibiting three distinct regions: linear elastic, long collapse plateau, and densification that made them particularly applicable for energy absorption. Volume fraction affected the layer collapse. The elastic geometrical stiffness increased for higher volume fractions and smaller cells. In addition, the peak and plateau stresses increased at higher volume fractions, and while smaller cells were not directly affected, the area under the curves were. Hence, for most materials, specific energy absorption was larger for higher volume fractions and smaller cells. The constituent material properties contributed significantly to the structural behavior, exhibiting three primary deformation mechanisms, i.e., elastomeric, elastic-plastic, and elastic-brittle, resulting in a wide spectrum of properties for each application requirement. The comparison of the optimal properties with the expanded polystyrene demonstrated the ability of sheet gyroid structures to overcome most of its challenges, exhibiting a superior specific energy absorption, ability to withstand various impacts, letting air flow in its all axes, and being recyclable. Thus, sheet gyroid structures can be considered promising alternatives.

Keywords: Periodic cellular lattice structures, triply periodic minimal surfaces (TPMS), additive manufacturing, compression, energy absorption, thermoplastic 


\section{Introduction}

For the last 50 years, the solution for impact absorption in lightweight applications has been the use of foams such as expanded polystyrene (EPS). However, EPS has various disadvantages such as insufficient specific energy absorption ${ }^{9}$, inability to absorb more than one impact ${ }^{6}$, thermal insulation ${ }^{10}$, and complicated recyclability.

Through millions of years of evolution, nature has formed extremely efficient structures such as honeycombs, insect shells, and trabecular bones ${ }^{12}$. Today, mathematical studies and additive manufacturing (AM) have enabled us to model, study, and apply these structures, auguring their important roles in future biomedical, automotive, and aeronautical challenges.

Among these structures, the triply periodical minimal surfaces (TPMSs) ${ }^{23},{ }^{24}$ exhibited potential advantages over strut based lattices. TPMSs are minimal-area localization periodic structures in three-coordinate directions with zero mean curvatures, free of intersections or straight lines.

They exhibit better additive manufacturing properties as continuous curves enable previous layers support subsequent layers not needing support ${ }^{32},{ }^{35},{ }^{33}$, contrary to strut-based structures, which are angle limited ${ }^{18}$. Additionally, open cells can easily exclude powder or liquid resin.

Strut-based structures can experience stress concentrations near the joints of the struts where geometrical continuity of TPMSs exhibit uniform stress distribution ${ }^{18},{ }^{28}$, 36, ${ }^{1}$. In a comparison by Lei Zhang et al. ${ }^{36}$ TPMS sheet-primitive, -diamond, and gyroid exhibited superior stiffness, plateau stress, and energy-absorption ability to strutbased body-centered cubic lattices. Aremu et al. ${ }^{5}$ compared variants of body-centered cubic (BCC), face centered-cubic (FCC), and gyroid cells, and observed that the variants of FCC, face-centered cubic with vertical struts (PFCC), and double gyroid (D- 
gyroid) performed better. Bobbert et al. ${ }^{7}$ recorded a $60 \%$ yield stress on fatigue endurance limit with sheet TPMS, contrary to the previous materials at $\approx 20 \%$. Speirs et al. ${ }^{29}$ also observed that TPMS exhibited a superior fatigue resistance and attributed the results to nodal points acting as cracking initiators.

Studying TPMS structures, Kapfer et al. ${ }^{13}$ and Ketan et al. ${ }^{3}$ demonstrated that sheet- or shell-like TPMS exhibited superior mechanical properties to TPMS-based skeletal networks. Maskery et al. ${ }^{16}$ observed that sheet gyroids have a specific energy absorption (SEA) approximately three times higher than that of BCC structures analyzed in a previous study ${ }^{17}$.

Regarding anisotropy, Aremu et al. ${ }^{5}$ observed that sheet gyroids have axisymmetric stiffness, unlike the other strut-based lattices tested. Chen et al. ${ }^{8}$ also concluded that sheet gyroids have a higher isotropy, maintaining the Zener ratio constant to unity for all densities contrary to the other TPMS structures: Neovius, diamond, Schwarz P, and even octet+cubic forms. In the investigation by Li et al. ${ }^{15}$, a sheet gyroid had similar isotropy for all densities, while a strut gyroid had apparent anisotropy. From all the previous studies, we can conclude that TPMS sheet structures have an overall superior manufacturing and mechanical performance, with sheet diamonds and gyroids being the best when considering isotropy. In addition, other studies have revealed also their outstanding properties in terms of thermal ${ }^{25}$, vibration ${ }^{27}$ and noise insulation. Additionally, their internal porous structure could also be applied to generate prosthesis ${ }^{31}$ in which the cells grown inside.

However, little is known about the effect of the variables of sheet gyroid structures for different polymeric materials and their behavior on energy-absorption performance as substitutes for current impact-absorption materials such as EPS. 
In relationship with the previous studies of the capability of TPMS to absorb energy, it must be highlighted that, despite there are some experimental studied of the behavior of these materials under quasi static load or with a low strain rate $\left(0.001 \mathrm{~s}^{-1}\right.$ to $\left.0.01 \mathrm{~s}^{-1}\right)^{20,26,30}$, there are only a few that study these materials under dynamic loads and analyzes the influence of the strain rate. In the case of McKown et al. ${ }^{19}$, they study the behavior of octahedral lattice structure under quasi-static and low strain rate (0.001 to $\left.0.5 \mathrm{~s}^{-1}\right)$ load cases and also under blast loading $\left(10^{3} \mathrm{~s}^{-1}\right)$ using a drop tower. In the blast studies, they observed that yield stress increases significantly for high strain rates and the failure mechanism changed. There are other studies that analyzed the influence of the strain rate of different 3D printed structures for cores of a sandwich structure 2,11,14,21. The results indicated that the average values of the stress-strain curve increases with the strain rate and, for high strain rate, different failure mechanism appeared. With regards to the most common AM techniques for TPMS, selective laser melting (SLM) and fused deposing modeling (FDM) for polymeric materials and direct laser melting (DMLM) for metals. In this study, four different thermoplastics are going to be studied because the generated TPMS will offer more closed mechanical properties to the EPS ones. In addition, DMLM will generate structures too stiff and we do not have access to sufficiently extended range of materials that could be used in SLM.

The aim of this article is to study the different variables affecting the energyabsorption performance of sheet gyroids for different FDM thermoplastics. Finally, we establish a comparison of their optimal configurations with those of EPS. It must be pointed that dynamic load test would be essential to determine the influence of the strain rate in the mechanical properties so it would be studied in future works. 


\section{Materials and methods}

\subsection{Gyroid lattice design}

TPMS gyroid can be approximated using the level curvature equation (Eq. 1) which, when plotted, results in the surface shown in Fig. 1a where $a$ is the unit cell size (Fig. 1b) and $t$ determines the volume fraction of the regions that are separated by the surface ${ }^{22}$.

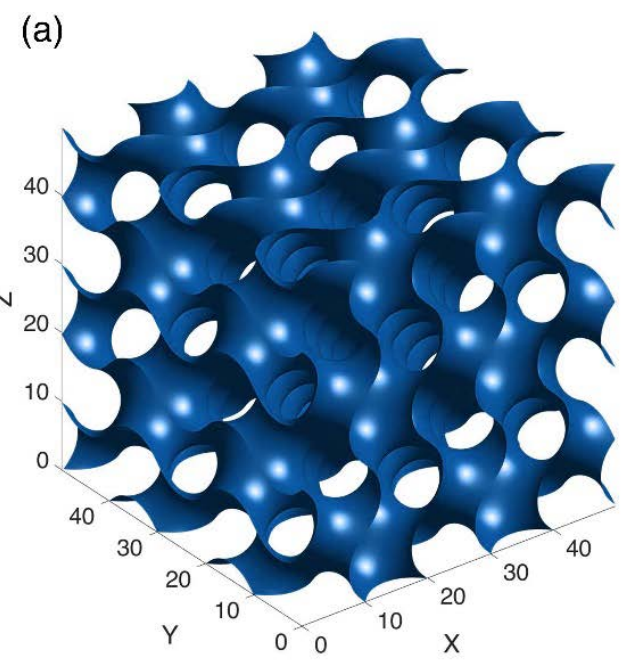

(b)
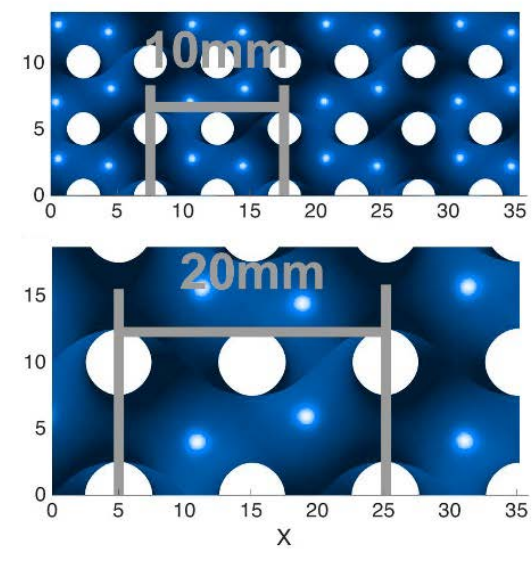

Figure 1. (a) Gyroid model generated in MATLAB, and (b) cell size comparison.

$\mathrm{F}(\mathrm{x}, \mathrm{y}, \mathrm{z})=\sin \left(\frac{2 \pi x}{a}\right) \cos \left(\frac{2 \pi y}{a}\right)+\sin \left(\frac{2 \pi y}{a}\right) \cos \left(\frac{2 \pi z}{a}\right)+\sin \left(\frac{2 \pi z}{a}\right) \cos \left(\frac{2 \pi x}{a}\right)-t$

Two main approaches can be employed to generate a solid gyroid. The first, often referred to as a network, strut, or skeletal gyroid, is created by considering one of the subdomains divided by the surface as a solid. As previously mentioned, this type exhibited the worst mechanical performance owing to stress concentration on the joints.

The second, and the one considered in this research, termed sheet-based or double gyroid, can be obtained by plotting two minimal surfaces with two different level-sets of the constant $t$ together, resulting in an offset from a hypothetical surface at the average of the two level-set surfaces. This specimen has been adjusted to obtain the desired volume fraction; it must also be highlighted that this volume fraction is equal to 
the relative density of the specimens. Fig. 2 shows all the tested specimens in function

of the period and the volume fraction.

\begin{tabular}{|c|c|c|c|c|c|}
\hline & $10 \%$ & $15 \%$ & $20 \%$ & $25 \%$ & $30 \%$ \\
\hline 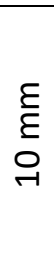 & 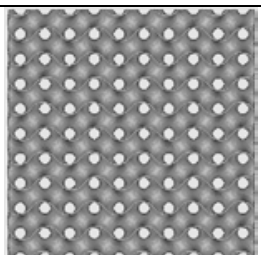 & 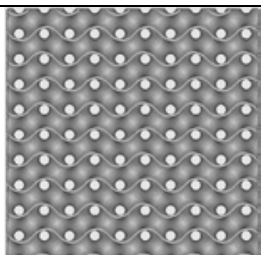 & 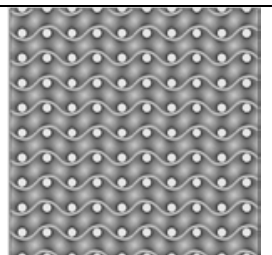 & 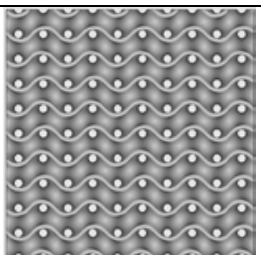 & 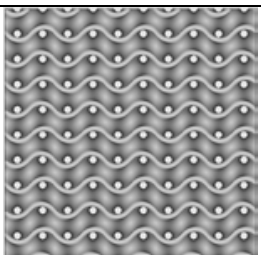 \\
\hline $\begin{array}{l}\xi \\
\xi \\
\stackrel{\xi}{\sim}\end{array}$ & 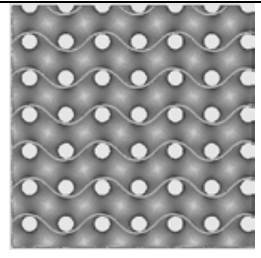 & 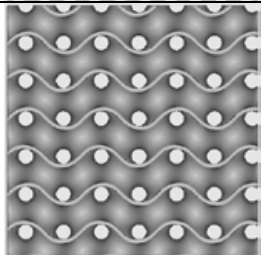 & 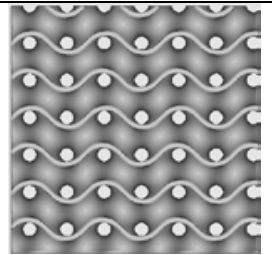 & 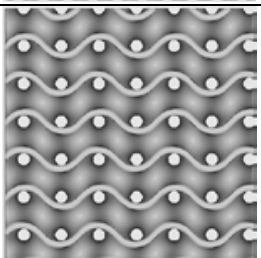 & 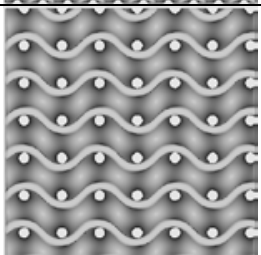 \\
\hline $\begin{array}{l}\xi \\
\underline{\varepsilon} \\
\text { ○ }\end{array}$ & 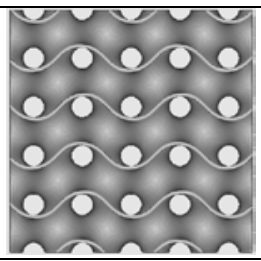 & 9 & & 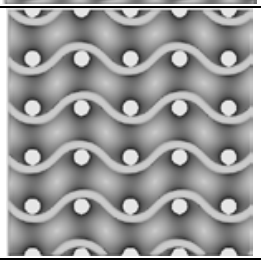 & 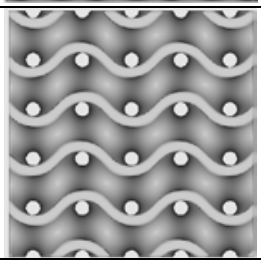 \\
\hline
\end{tabular}

Figure 2. Solid Sheet gyroid specimens with different volume fractions and periods

\subsection{Specimen fabrication, materials, and printing conditions}

Following the ISO 844:2015 standard for polymeric cellular structures, 50-mm cubic specimens were fabricated with the previously observed variables: cell size $a(10,20$, and $25 \mathrm{~mm})$, volume fraction $t(15,20$, and 25\%) and different materials: polylactic acid (PLA), acrylonitrile butadiene styrene (ABS), thermoplastic polyurethane (TPU), and polyamide 12 (PA12) (Table 1).

Additionally, owing to the maximum load capability of the universal test machine used, to compare the performance of each material when adopting the sheet gyroid structure, we tested 25-mm cubic specimens with 100\% infill (Table 2).

The nomenclature used to name the specimens was CCaDD\%MMM where CCa stands for the variable $a$ (cell size), DD\% for the volume density and MMM for the material acronym. For example, a specimen $15 a 15 \%$ PA12 is a structure with a cell size of $15 \mathrm{~mm}, 15 \%$ volume fraction, made of polyamide 12. 
Specimens were printed via FDM technology using a Zortrax M300. The samples were prepared with a layer thickness of $0.1 \mathrm{~mm}$, nozzle size $0.4 \mathrm{~mm}$, and $100 \%$ infill. The temperature, retraction distances, or layer ventilation were selected considering the characteristics of each material. A desiccant box with a guided tube to the direct extruder was used to avoid hygroscopy on the nylon filament.

Table 1. Basic mechanical properties of the materials provided by the manufacturer.

\begin{tabular}{llccccc}
\hline Manufacturer & $\begin{array}{c}\text { Tensile } \\
\text { Strength } \\
\mathbf{( M P a )}\end{array}$ & $\begin{array}{c}\text { Tensile } \\
\mathbf{M o d u l u s} \\
\mathbf{( M P a})\end{array}$ & $\begin{array}{c}\text { Flexural } \\
\text { Modulus } \\
\mathbf{( M P a )}\end{array}$ & $\begin{array}{c}\text { Elongation } \\
\text { at Break } \\
\mathbf{( \% )}\end{array}$ & $\begin{array}{c}\text { Density } \\
\left(\mathbf{g} / \mathbf{c m}^{3}\right)\end{array}$ \\
\hline PLA & HR-870 & 32 & 2447 & 1979 & $\mathrm{n} / \mathrm{a}$ & 1.22 \\
& ZORTRAX & & & & & \\
ABS & ULTRA & 30 & $\mathrm{n} / \mathrm{a}$ & 1080 & 11.08 & 1.195 \\
TPU & FFF Flexismart & $\mathrm{n} / \mathrm{a}$ & $\mathrm{n} / \mathrm{a}$ & $\mathrm{n} / \mathrm{a}$ & 600 & 0.96 \\
PA12 & Fiberology & $\mathrm{n} / \mathrm{a}$ & 1400 & 1200 & $\mathrm{n} / \mathrm{a}$ & 1.02
\end{tabular}

Table 2. Basic mechanical properties of the materials of $100 \%$ volume fraction specimen under compression.

\begin{tabular}{llccc}
\hline & Manufacturer & $\begin{array}{c}\text { Tensile } \\
\text { Strength (MPa) }\end{array}$ & $\begin{array}{c}\text { Tensile } \\
\text { Modulus (MPa) }\end{array}$ & Density (g/cm $\left.{ }^{\mathbf{3}}\right)$ \\
\hline PLA & HR-870 & 68.79 & 1936.54 & 1.22 \\
& ZORTRAX & & & \\
ABS & ULTRA & 69.18 & 1692.64 & 1.195 \\
TPU & FFF Flexismart & - & 20.58 & 0.96 \\
PA12 & Fiberology & 48.22 & 1491.91 & 1.02
\end{tabular}

The approach used PLA as a reference to test the effect of cell size and density. As cell size did not have a significant effect on the performance, the next batch of materials, ABS and TPU, was tested at 15-mm cell size. Finally, due to its known tenacity, PA12 was tested.

The comparison with current materials used for impact absorption for lightweight applications were taken from a previous study for EPS specimens of 60, 80, 
100, and $120 \mathrm{~kg} / \mathrm{cm}^{3}$. These specimens, which had a $50 \mathrm{~mm}$ cubic geometry, were mechanized using a Roland MDX 20 CNC milling machine.

In addition, solid cube specimens were also tested to determine the mechanical properties of the original material under compression efforts (Fig. 3). It can be observed that all the materials follow the Ashley-Gibson material model.
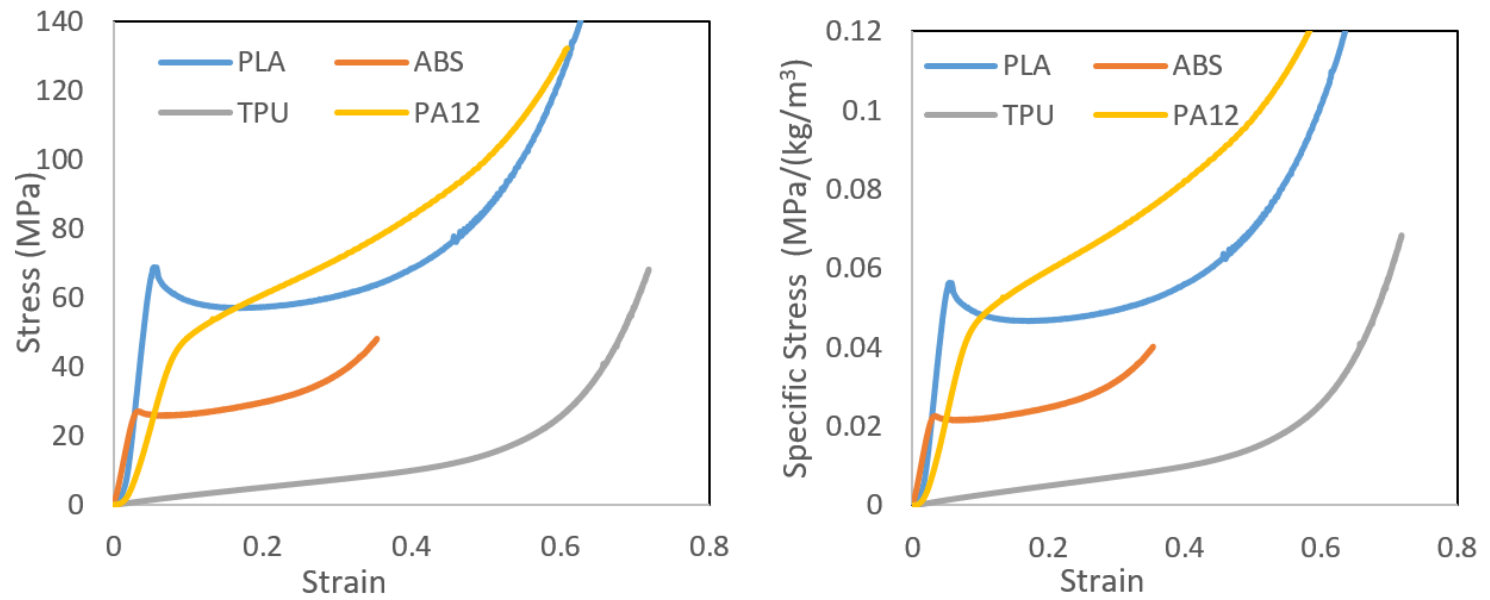

Figure 3. Left: stress-strain curve of the solid material under compression efforts; right: specific stress-strain curve of the solid material under compression efforts

\subsection{Mechanical testing}

Uniaxial compression tests were performed on an Instron 8032 equipped with a 100-kN load cell, with a constant strain rate of $5 \mathrm{~mm} / \mathrm{min}$ following the ISO 844:2015 standard. The compression test was conducted in the build direction (z) to avoid the build orientation effect.

During the test, photographs were captured to observe the failure behavior and perform an extensometer analysis using digital image correlation (DIC) on the software GOM Correlate.

\section{Results and discussion}

\subsection{Effects of volume fraction}

Fig. 4 shows representative stress-strain curves of the compression behavior of the structure, at 
a fixed $15-\mathrm{mm}$ cell size and 10,15, 20, 25, and 30\% volume fraction. The behavior for all specimens began with linear elastic regime controlled by bending of the cell wall affecting all layers (Fig. 4) at approximately 5\% strain frame, noticeable by the circles turning into ovals.

(a)

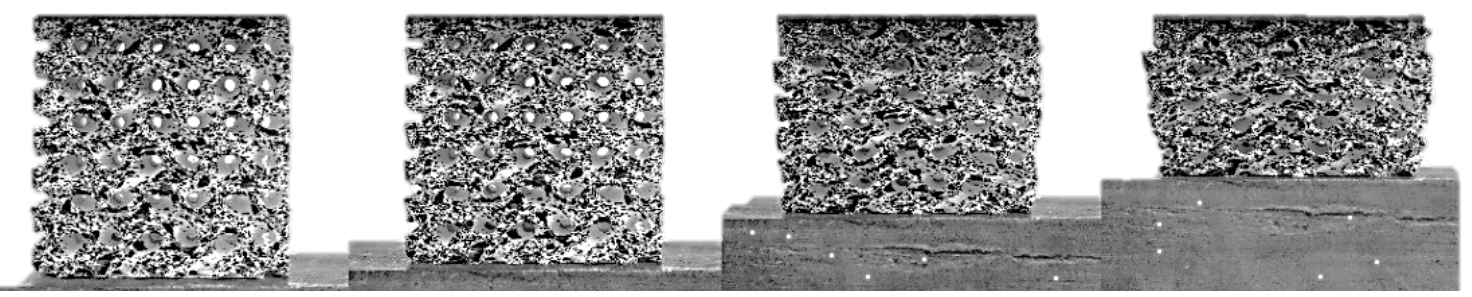

0.0

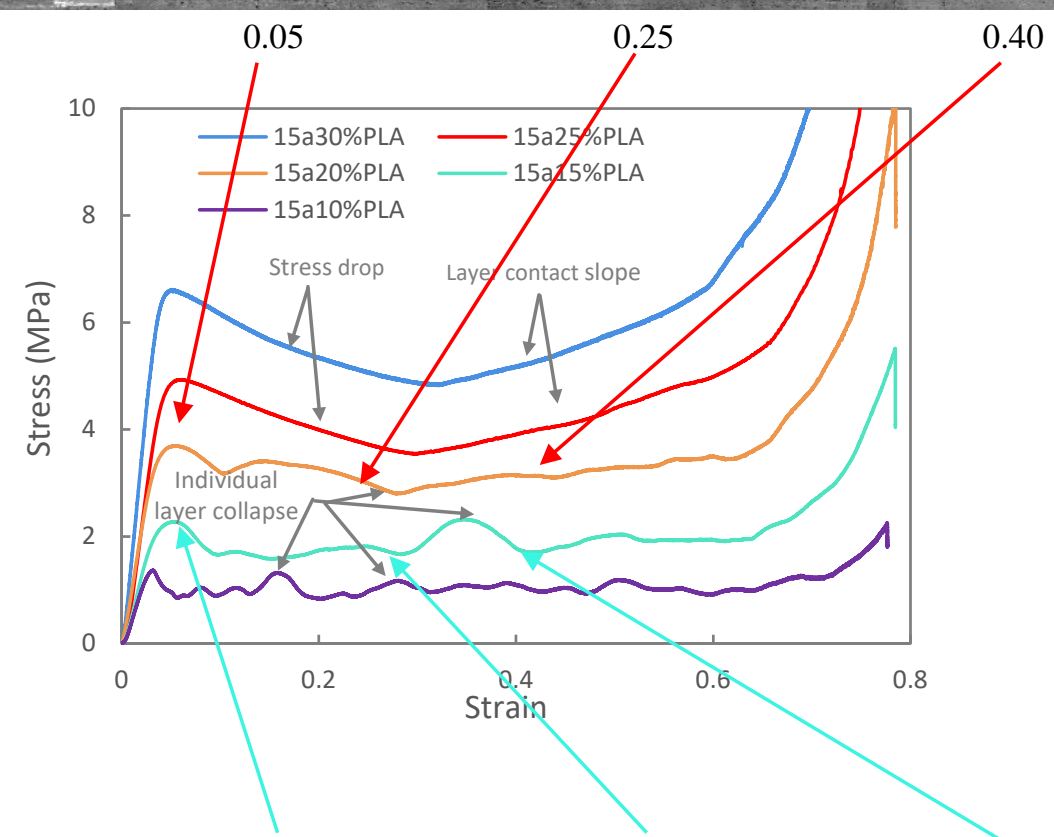

(c)

(b)

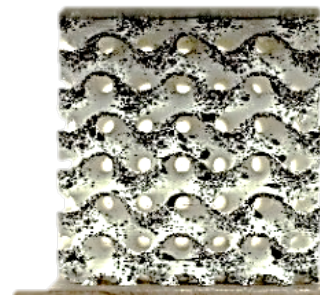

0.0

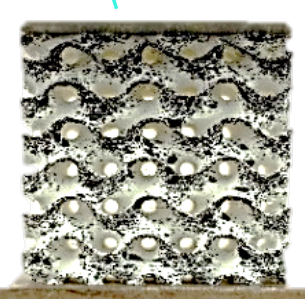

0.05

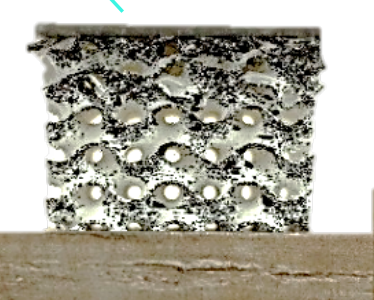

0.25

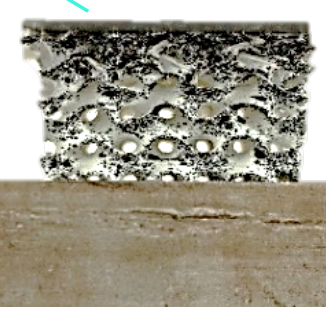

0.40

Fig. 4. Representative stress-strain curve of 15-mm cells and different volume fractions of PLA (b). Deformation stages of (a) 15a25\%PLA and (c) 15a15\%PLA. Captions in the images: strain. 
When the elastic limit was attained, the stress-strain curve exhibited a long collapse plateau, associated with the formation of plastic hinges on the walls. Here, two types of collapse were observed:

At higher densities, such as 25 and 30\%, the collapse continued for all the layers simultaneously (Fig. 4a) beyond the elastic region, which correlated to a single drop after the peak stress and to the slope prior to densification. This was produced by the yielding of all layers together and the subsequent contact with each other, which required higher stress to be compressed further.

Lower densities, such as 10, 15, and 20\%, exhibited a layer-by-layer collapse (Fig. 4c), where this process was repeated on each layer, correlated to the slope oscillations on the 10, 15, and 20\% specimens shown in Fig. 4b.

Finally, in both scenarios, when all cells were virtually completely collapsed, opposing cell walls could not be compressed further, beginning densification in which stress increased steeply.

The increase in density resulted in a higher modulus, which was also observed for the other cell sizes (Fig. 5a). Higher volume fractions affected higher compression stress, exhibiting a linear increase in both peak stress (Fig. 5b) and collapse plateau stress (Fig. 5c) consistent with the Gibson-Ashby model 12.

Densification was produced earlier as volume fraction increased, beginning densification at $60 \%$ strain for the $30 \%$ volume fraction and up to $73 \%$ for the $10 \%$ specimen (Fig. 5d). This behavior was related to the description in Section 2.1, as density was determined by a larger wall offset; this resulted in an earlier contact between layers and a higher final solid volume producing premature densification.

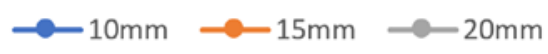



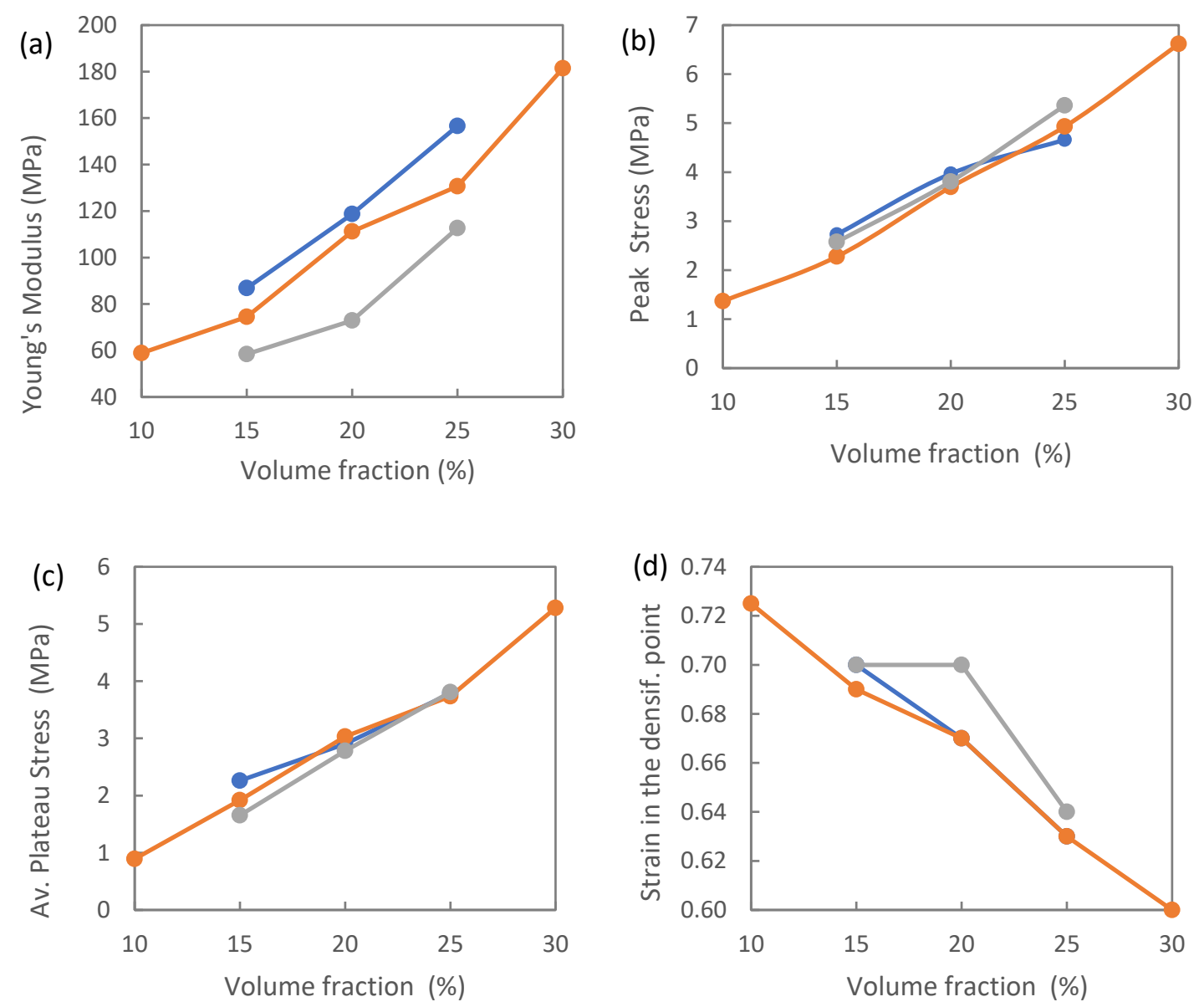

Figure 5. Main mechanical properties vs. volume fraction for different cell sizes.

Fig. 6 shows the plots of the specific stress of 15-mm cells of various volume fractions. The next specimens of 10 and $30 \%$ volume fractions were also tested to confirm the trend values. The figure shows that while the 10,15 , and $20 \%$ specimens exhibited larger differences, the 25 and 30\% specimens did not exhibit any more gain. This was possibly related to manufacturing conditions, as layer adhesion, overhangs or nozzles, and thickness ratios did not attain the optimal minimum values until the $20 \%$ fraction. As the result of the specific energy absorption indicated (Fig. 7), 5\% volume increments exhibited a 17 and $18 \% \mathrm{~kJ} / \mathrm{kg}$ gain until 20\% but showed no further gain at 25 and 30\%. This behavior could lead to a more efficient selection of structure volume fraction, saving print time, materials, and energy. Furthermore, comparing the specific 
mechanical properties of these structures (Fig. 6) with the original solid ones (Fig. 3) it can be observed that, for all the materials the densification point appears later with the gyroid structures what implies also that the plateau comprises a higher strain range which implies that the absorption of energy will span a higher deformation; in addition, the initial peak after the elastic zone decreases for the PLA and the ABS. However, the specific stress levels in the plateau zone decreases what implies that these structures can absorb less energy than the solid original material.

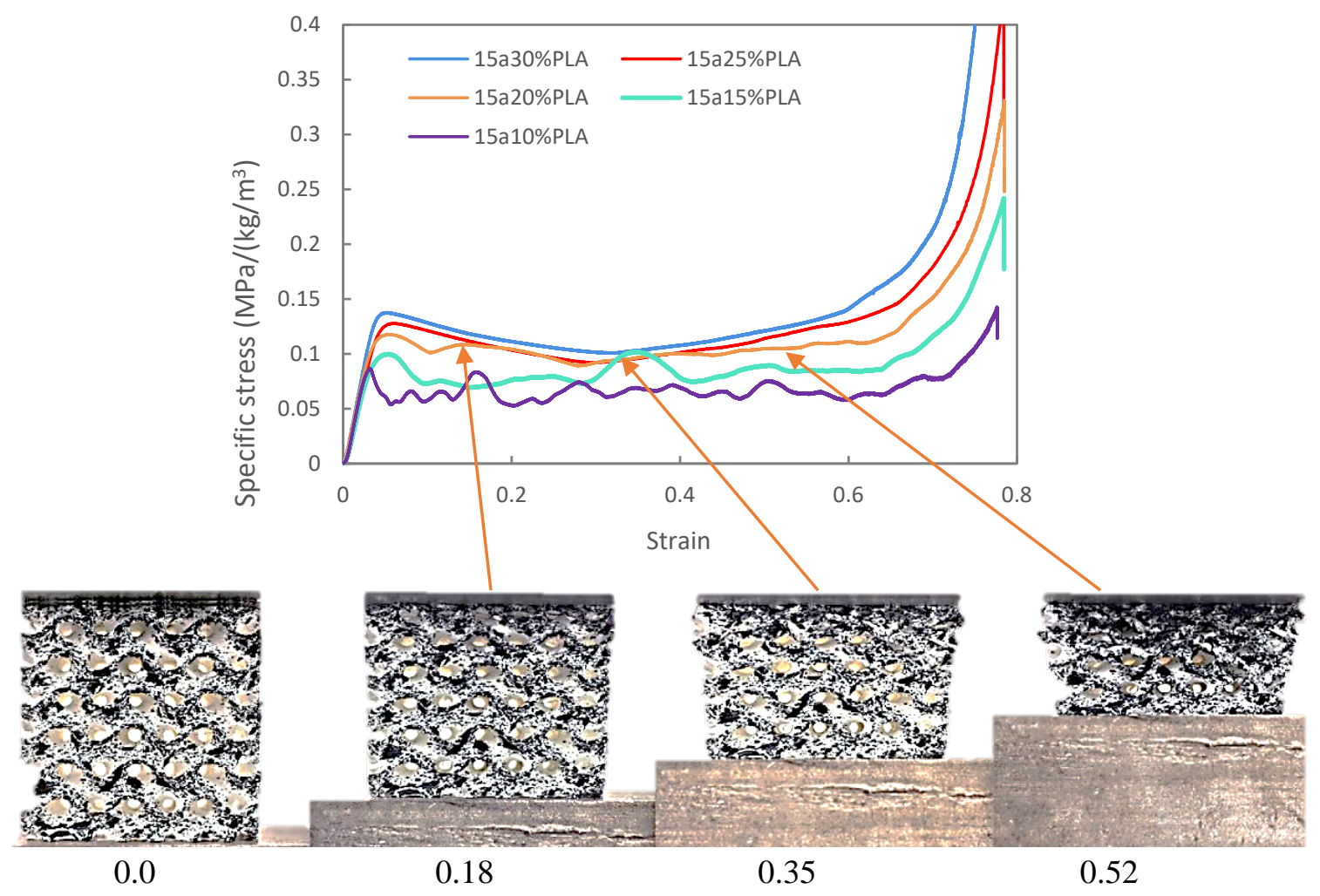

Figure 6. Specific stress-strain curves of 15-mm cells for different PLA specimens (a). Deformation stages of 15a20\%PLA (b). Captions in the images: strain. 


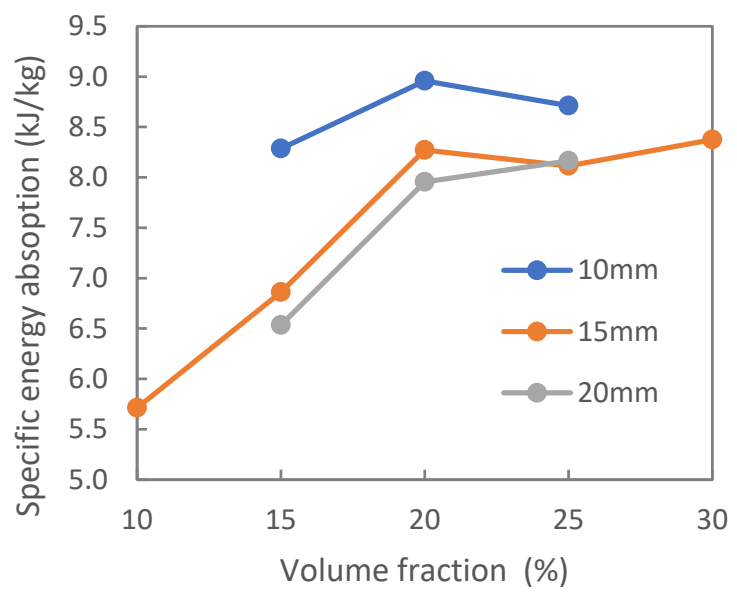

Figure 7. Specific energy absorption vs. volume fraction for different cell sizes.

\subsection{Effects of Cell size}

Fig. 9 depicts representative stress-strain curves for 10-, 15-, and 20-mm cells at a fixed volume fraction of 20\%. Smaller cell sizes exhibited higher an elastic geometrical stiffness, obtaining 118.68, 111, and $72 \mathrm{MPa}$, respectively, which was also observed for the other volume fractions (Fig. 10a). This behavior was further analyzed on GOM Correlate (Fig. 10), in which the walls between layers, shown in turquoise in the figure, exhibited a higher negative strain. Here, the slenderness of larger cells could favor this flexion over smaller cells.

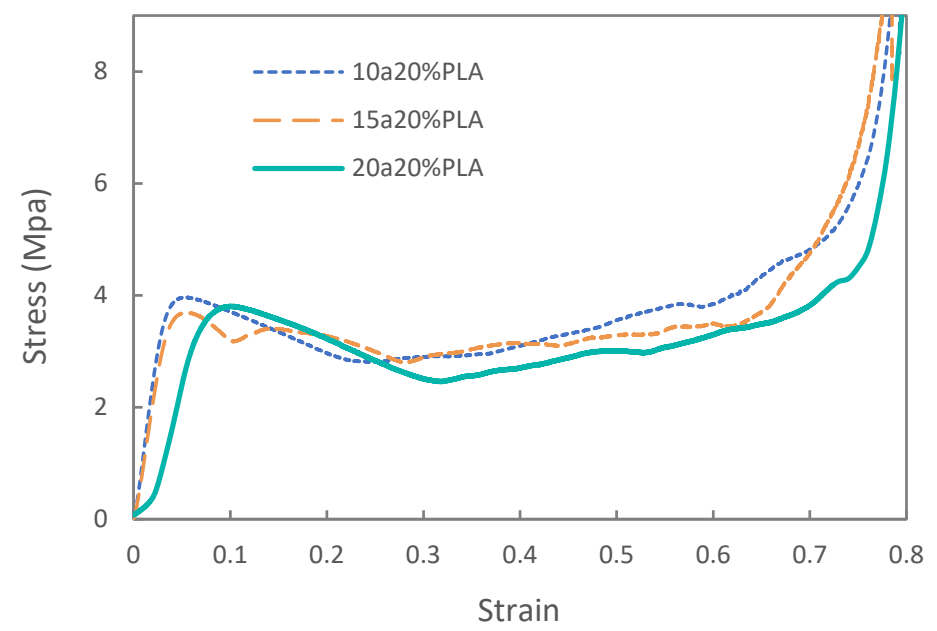

Figure 8. Stress-strain curve for 10-, 15-, and 20-mm cell sizes at 20\% volume fraction. 


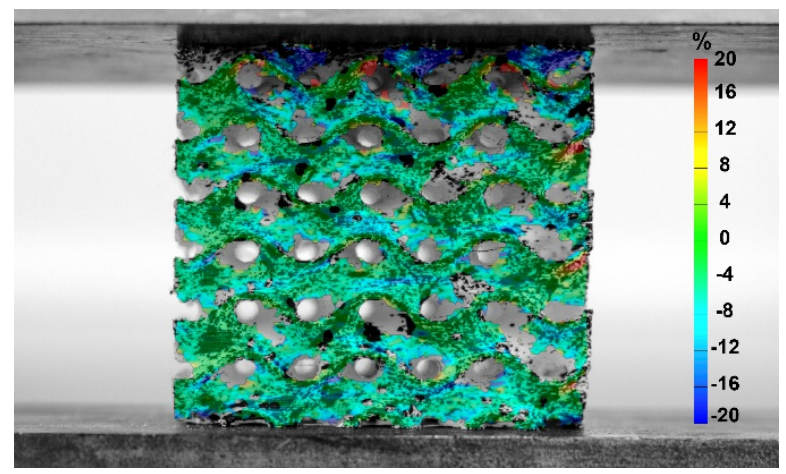

Figure 9. GOM extensometer analysis on a 15a20\%PLA and $\mathrm{z}$ strain (\%).

Another noticeable difference between cells sizes was the presence of a toe region with non-linear concave beginning on the $20 \mathrm{~mm}$ cell specimens. This artefact was caused by an initiation of slack, alignment, and the bending of the non-completed layers at the limit of the specimen.

While peak stress was not directly affected by cell size (Fig. 10b), the mean stress values or area under the curve exhibited slightly higher values for lower size cells (Fig. 10c). The curves were progressively constant with increasing the density until the $25 \%$ volume fraction.

This decrease in compressive strength as cell size increases has been previously observed for an Al-Si10-Mg sheet gyroid lattice in the study from Maskery et al. 16. In their study, the strength difference was higher, presumably owing to the presence of brittle fracture, crack propagation, and diagonal shear, which are failures that the plastic behavior of PLA could have mitigated.

Other factors of AlSi10Mg strut gyroids promoting this behavior were proposed by Yan et al. 34: a better wetting condition during the DMLS process for the smaller cells and finer micro structure as a result of faster cooling and due to the ratio of specimen to cell sizes ${ }^{4}$. 
In most scenarios, smaller cells exhibited lower strength drop percentages (Fig. 10d), as previously observed with GOM Correlate for the elastic geometrical stiffness; after the elastic regime, larger cells and wall slenderness can favor buckling and hinge formation, leading to a lower stress deformation.
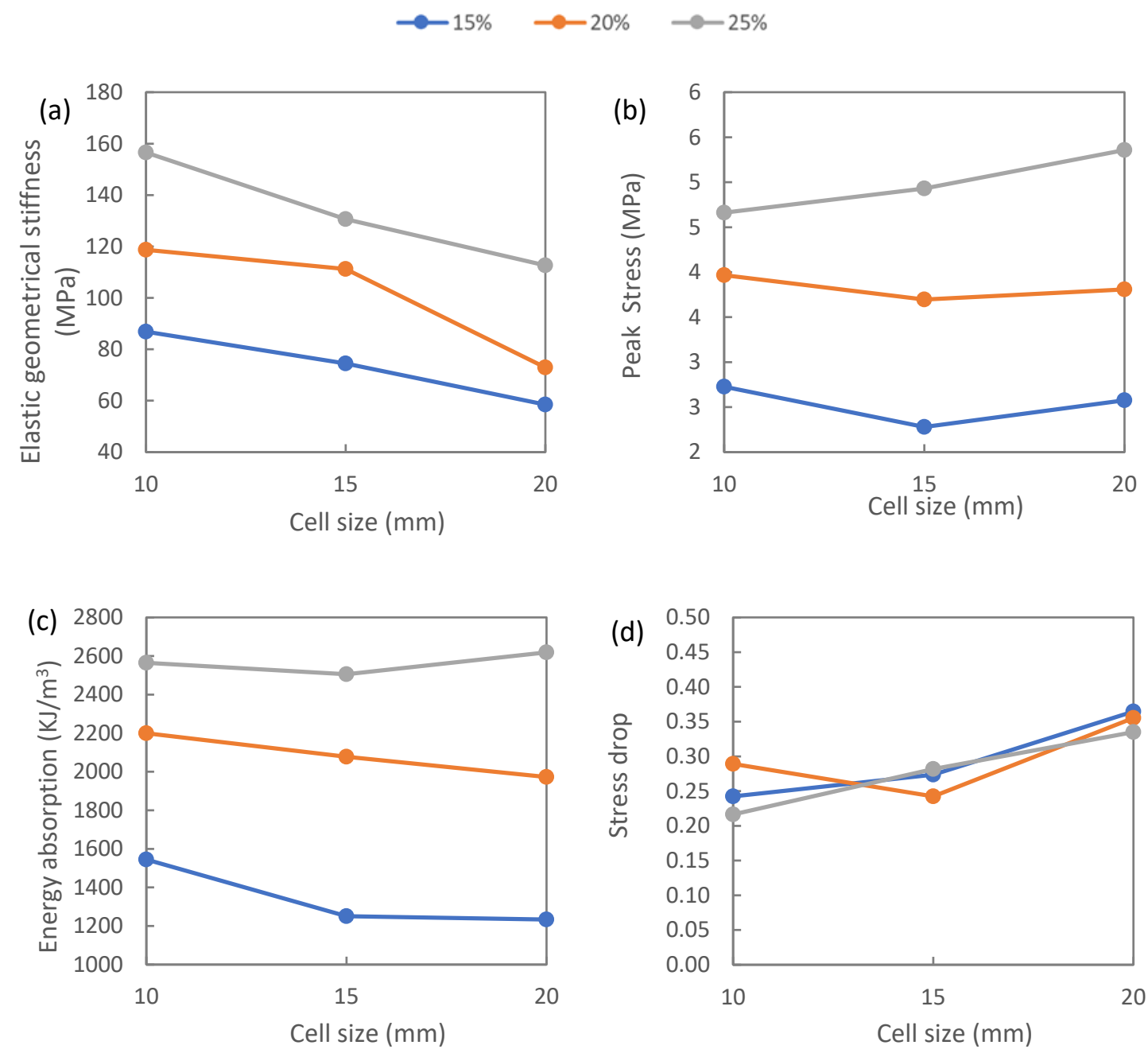

Figure 10. Effect of the cell size on the main mechanical properties for different volume fractions.

Fig. 11 shows the plot of the specific energy absorption with cell size as the function. Smaller cell sizes exhibited greater efficiency, with 10 -mm cells exhibiting the largest improvement over 15 -mm cells. The $15 \%$ volume fraction exhibited a $17 \%$ increase and 5\% on the $15 \mathrm{~mm}$ to $20 \mathrm{~mm}$. 


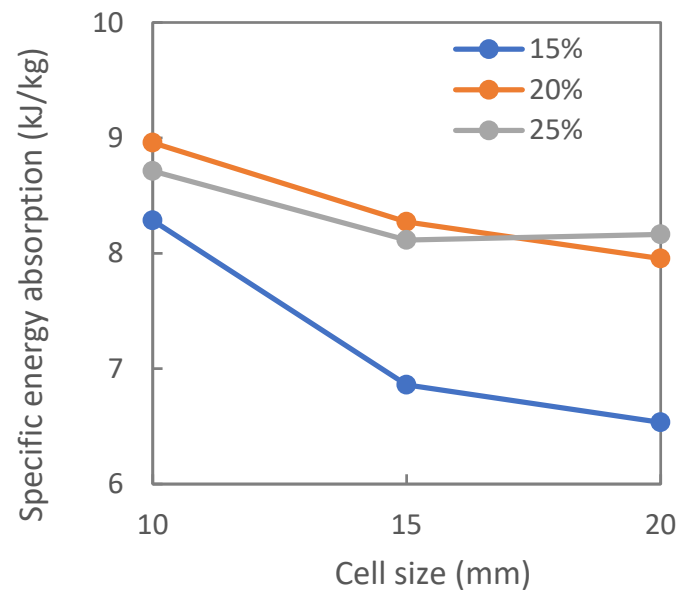

Figure 11. Specific energy absorption vs. cell size for different volume fractions.

\subsection{Effects of material}

As cell size did not exert a major effect, the remaining materials were tested at a cell size of 15 $\mathrm{mm}$. The behavior of the sheet gyroid lattice for the four materials tested exhibited the same behaviors described by Gibson and Ashby for foams, exhibiting three main deformation mechanisms: elastomeric, elastic-plastic, and elastic-brittle.

\subsubsection{ABS and PLA}

Fig. 12b depicts stress-strain curves for 25 and 20\% densities of PLA and ABS. Both exhibited an elastic-plastic behavior, beginning with a linear elasticity regime determined by wall bending and followed by a long plateau produced by layer collapse owing to cell walls yielding; ABS in particular exhibited a brittle-like perturbation due to cell fracture.
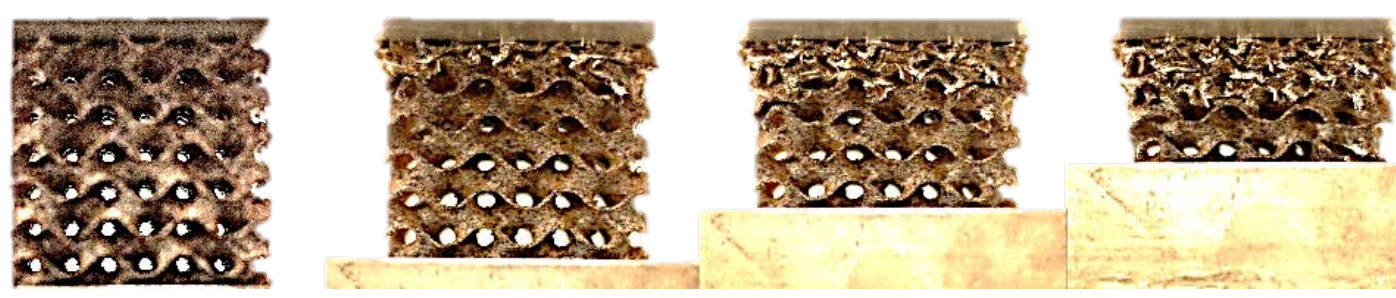

0.0

0.15

0.35

0.52 


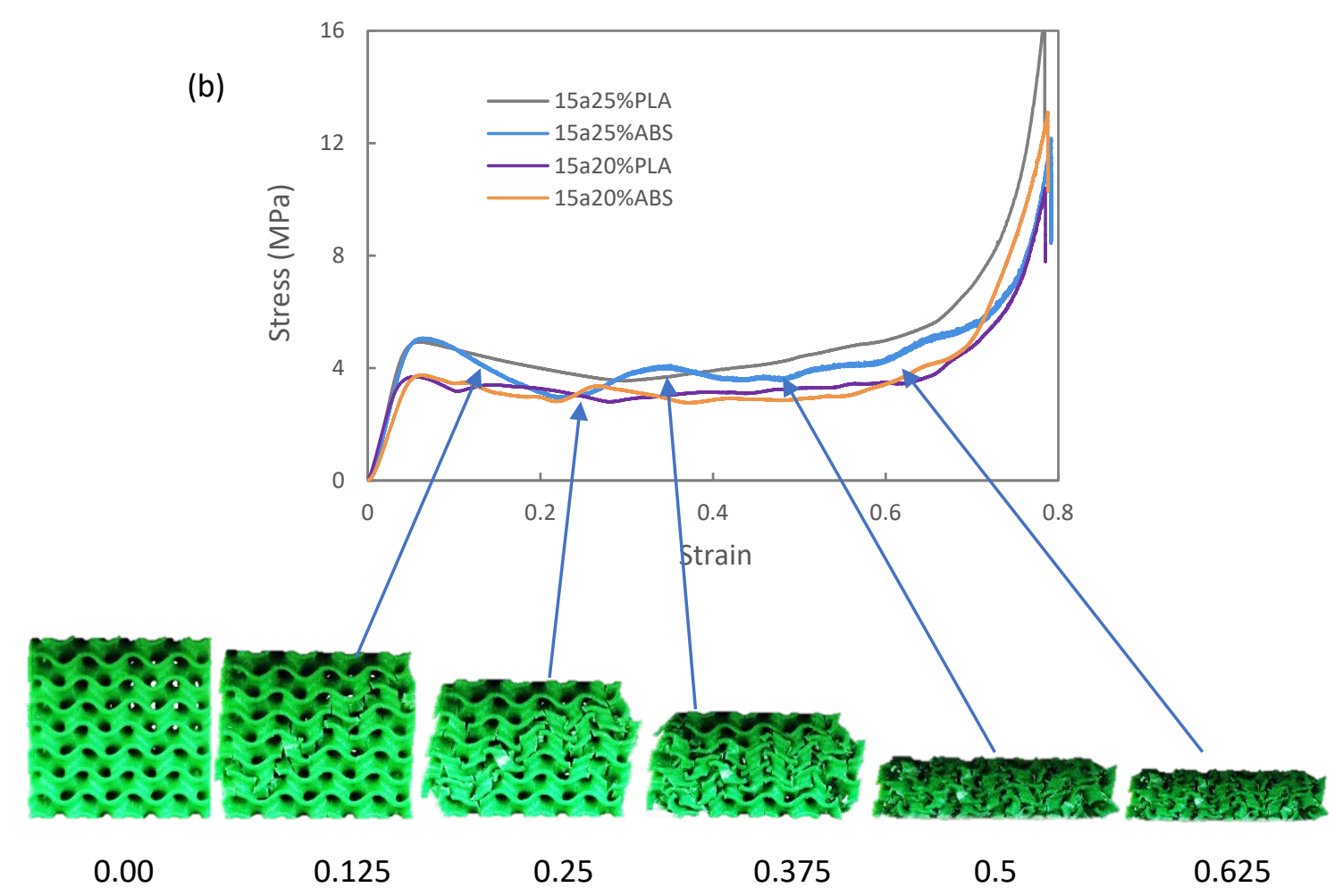

Figure 12. Deformation stages of 15a20\%ABS (a) and 1525\%ABS (c); (b) stress-strain curve for $15-\mathrm{mm}$ cell with a volume fraction of $20 \%$ and $25 \%$ for PLA and ABS. Captions of Figure 11 a: strain

Both PLA and ABS exhibited the highest module between all materials; PLA was stiffer at the higher densities, attaining 111.24 MPa against 93.23 MPa at 20\% (Fig. 15a).

As n Fig. 15b and 15c show, PLA and ABS also had the highest peak stress and the largest stress drop. This drop increased at higher densities, the highest being a 42\%, from 5.07 to $2.93 \mathrm{MPa}$, for a $25 \%$ volume of ABS. The stress loss could be related to an easier cracking propagation over brittle materials, further analyzed when comparing the layer collapse of PLA and ABS, shown in Figs. 4b and 11a, where the former shows how the cells tended to yield and the latter shows fractures on the cell walls.

The highest peak stress and the fact that ABS has lower density than PLA resulted in the best peak stress to weight ratio of all materials which was equally efficient at $0.15 \mathrm{MPa} / \mathrm{g}$ for all volume fractions (Fig. 15e). Coupled with larger strains 
than PLA (Fig. 15d), ABS had the highest specific energy absorption of all materials when considering a single compression, obtaining $10.49 \mathrm{~kJ} / \mathrm{kg}$ compared with 6.86 $\mathrm{kJ} / \mathrm{kg}$ for a $15 \%$ PLA specimen (Fig. 15f).

These properties make them ideal for high-strength, lightweight applications that have to withstand high-force single crash situations such as crash box cars, B pillars, or door panels.

\subsubsection{TPU}

(a)

As Fig. 13b shows, the elastomeric deformation of TPU began with a lower slope controlled by bending of cell walls. Although the collapse stress was far lower than those of ABS or PLA, a collapse plateau was produced by cell elastic buckling; hence, after densification, the specimen recovered its initial shape (Fig. 13a right image).
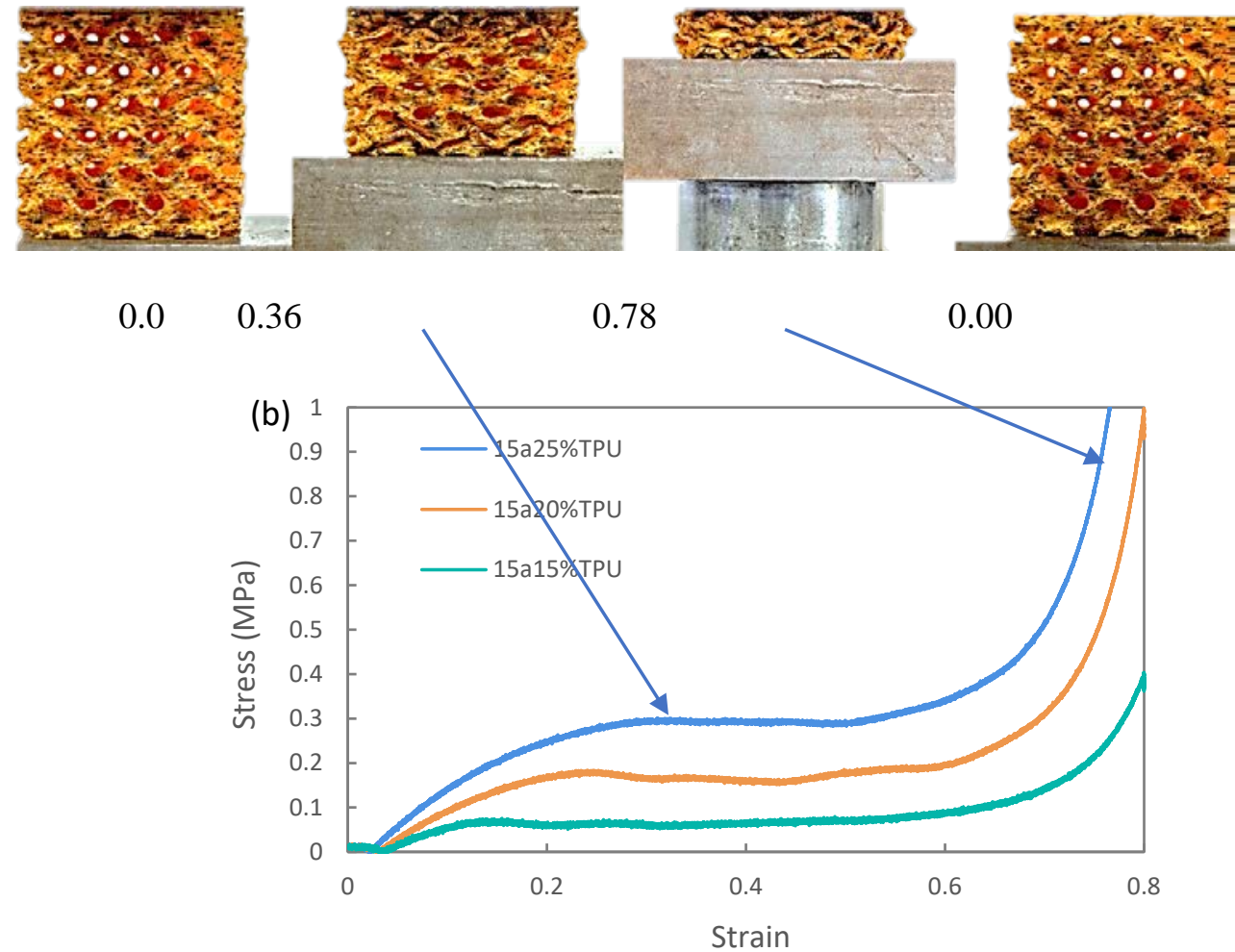

Figure 13. Deformation stages of 15a25\%TPU (a); stress-strain curve for $15 \mathrm{~mm}$ cell 15\%, 20\%, and 25\% volume TPU (b). Captions of Fig. 12 a: strain 
TPU exhibited smaller elastic geometrical stiffness and peak stress; for example, at $20 \%$ volume fraction, ABS was $98 \%$ stiffer, with 93.23 MPa compared with 1.24 MPa for TPU (Fig. 15a), and the max stress of TPU was $0.18 \mathrm{MPa}$ in contrast to 3.76 MPa for ABS (Fig. 15b).

Interestingly, TPU exhibited the least stress drop at all volume fractions, having half the stress drop percentage of ABS of $20 \%$ volume fraction (Fig. 15c). This behavior could be related to the novel elastic buckling of the TPU, contrary to the brittle cracking of ABS.

Despite volume fraction being the main factor affecting max strain, the stress required to produce an elastic crush of the walls, compared with the stress required to further compress the material itself when reaching densification, resulted in a noticeable stress increase, shortening the operative strain (Fig. 15d).

These properties made TPU have the lowest specific peak stress and specific energy absorption, which was $0.32 \mathrm{~kJ} / \mathrm{kg}$ against $9.82 \mathrm{~kJ} / \mathrm{kg}$ for ABS of $20 \%$ density (Fig. 15e and f).

All previous lower values can be compensated by the fact that after impact, TPU could virtually recover its entire shape, making it is suitable for multiple low stress impact situations such as American-football, boxing, or hockey helmets.

\subsubsection{PA12}

Fig. 14b shows the plots of the stress-strain curves of 15-mm cell, 25\% volume fraction of PA12 and ABS specimens; as the figure shows, PA12 exhibited an intermediate behavior between TPU, PLA, and ABS, i.e., elastoplastic and elastic foam, with an elastic geometrical stiffness modulus in between, a peak stress near the latter, and smooth transition without relative maximum preceding a novel collapse stress (Fig. 14a). Its main characteristic was that, after densification, it recovered up to $80 \%$ of its initial length, maintaining its absorbing energy in the two subsequent compression tests. 
(a)

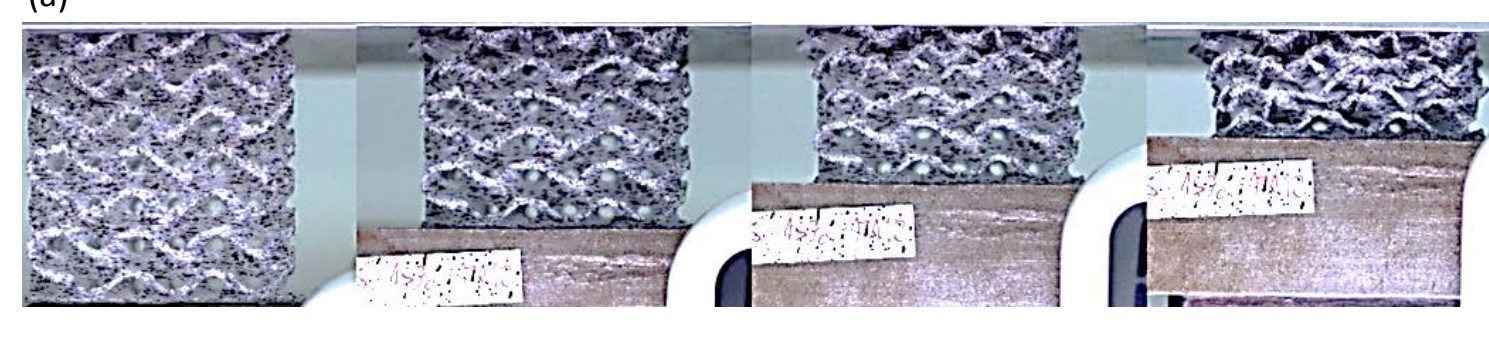

0.0

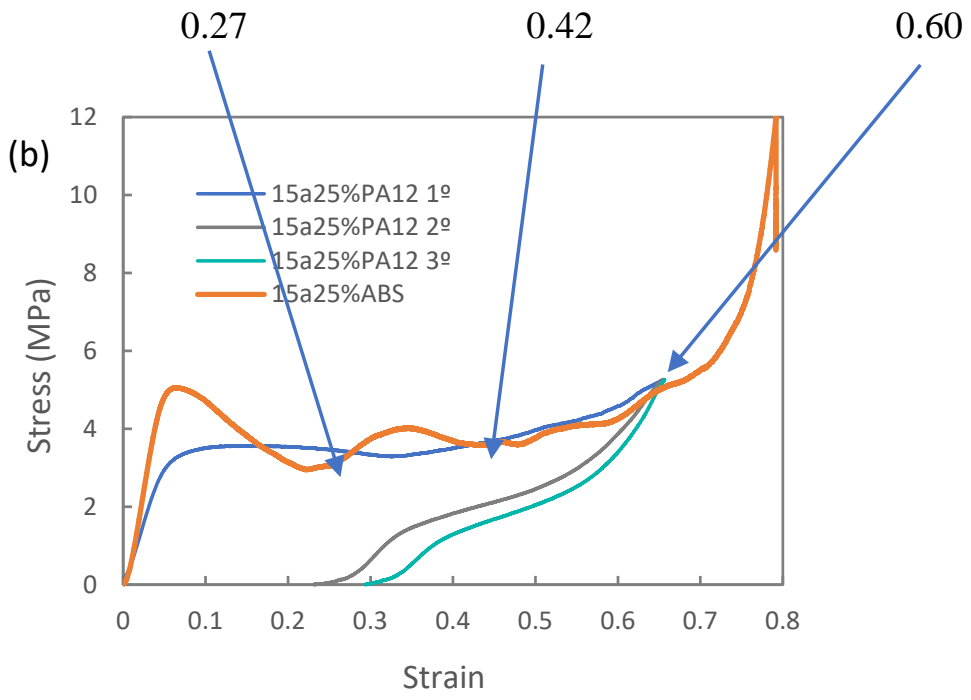

Fig. 14. (a) Deformation stages of 15a25\%; Stress-strain curves for 15-mm cell and $25 \%$ volume fraction for the ABS and PA12 with some consecutive loads

The elastic geometrical stiffness was approximately half that of ABS in all volume fractions, attaining 65.89 in contrast to $124.95 \mathrm{MPa}$ in the $25 \%$ volume fraction (Fig. 15a).

Although the maximum stress of PA12 25\% (3.51 MPa) was lower than that of ABS (5 MPa) (Fig. 15b), the novel collapse of PA12, free of oscillations, made it obtain one of lower stress drop values, maintaining a near-constant stress. Compared with those of ABS and PLA, the stress drops of TPU and PA12 were lower as volume fraction increased (Fig. 15c).

The peak stress of the second compression was lower than the initial loading, suggesting that the deformation on the first loading included elastic and plastic deformation. However, the curves of the second and third compression were similar, 
indicating a viscoelastic recovery. This was further confirmed when the specimen virtually recovered to their initial height a few days after.

The previous mentioned factors such as novel collapse stress near PLA and ABS, a large max strain, a lower specific density, and the ability to maintain the absorbing energy in subsequent compressions, caused PA12 to obtain the largest specific energy absorption of $14 \mathrm{~kJ} / \mathrm{kg}$ compared with $9.34 \mathrm{~kJ} / \mathrm{kg}$ for ABS of $25 \%$ volume.
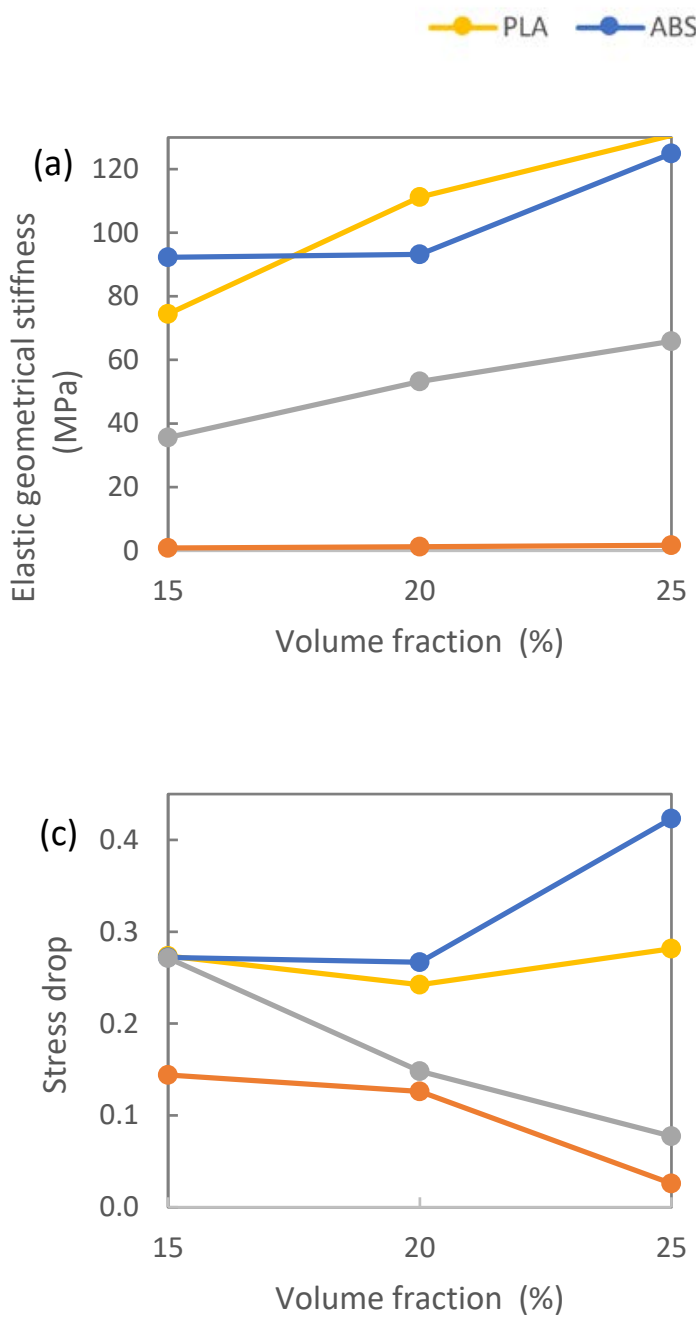
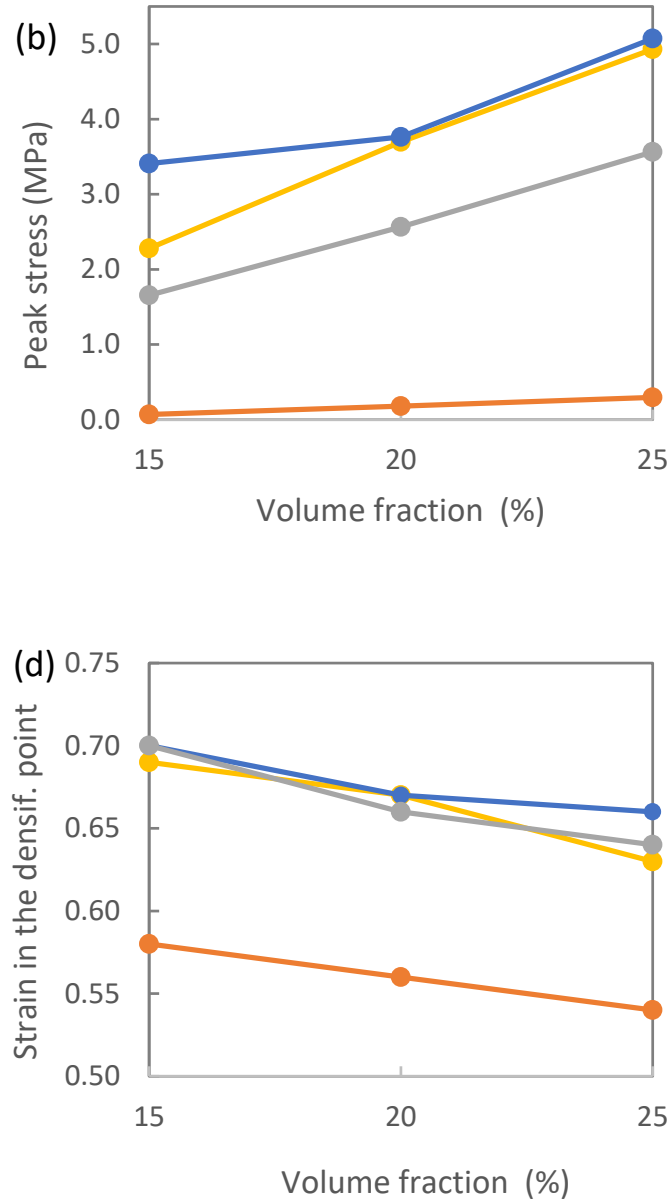

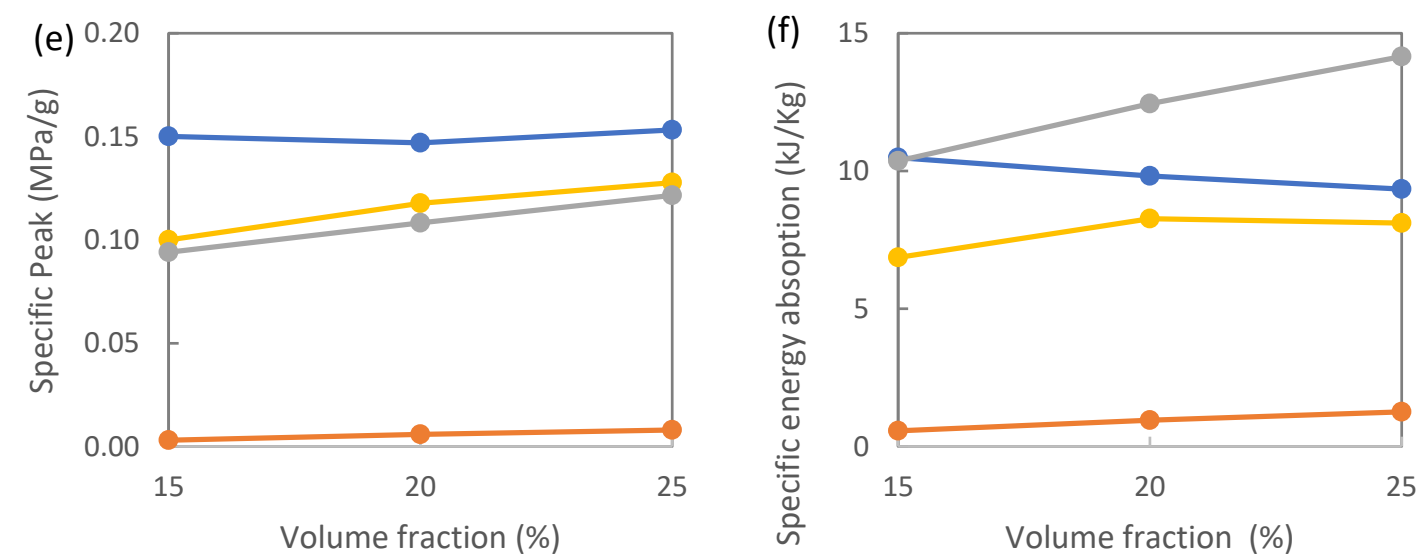

Figure 15. Effects of material mechanical properties.

These qualities made PA12 exhibit good performance on high-stress repeated impacts while maintaining good structural integrity, suitable for applications such as motorcycle or bike helmets, where traffic collision often implies multiple impacts against cars, pavements, and urban structures.

\section{Comparison of EPS Performance}

In this section, a comparative analysis of EPSs with different gyroid structures is discussed. Fig. 16 shows the stress-strain curves of 15a10\%ABS and EPS120; the sheet gyroid exhibited a peak stress of 2.88 MPa and a horizontal layer collapse at approximately 2.5 MPa, attaining densification at 68\%. EPS began its collapse at 1.7 MPa with a slope until 2.3 MPa, attaining densification at $40 \%$ strain. Hence, the specific absorbed energy for the ABS sheet gyroid was $9.28 \mathrm{~kJ} / \mathrm{kg}$ compared with $6.23 \mathrm{~kJ} / \mathrm{kg}$ for EPS, which was a 33\% increase in performance. 


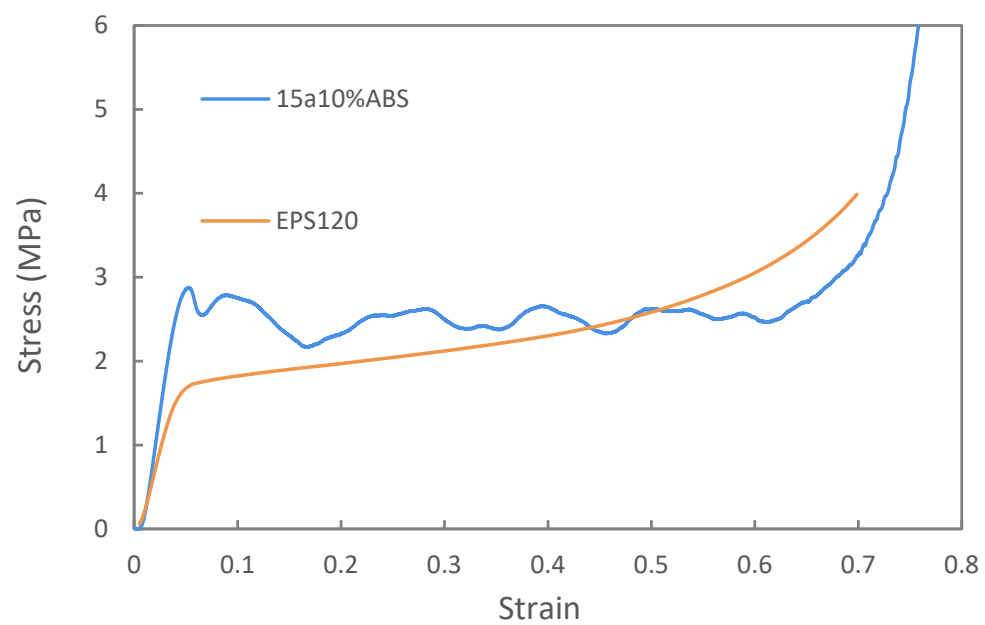

Figure 16. Stress-strain curves of 15a10\%ABS and EPS120.

In addition, the ABS gyroid exhibited a higher energy absorption per volume (Fig. 17), requiring less space to absorb the same amount of energy, thus using thinner shells.

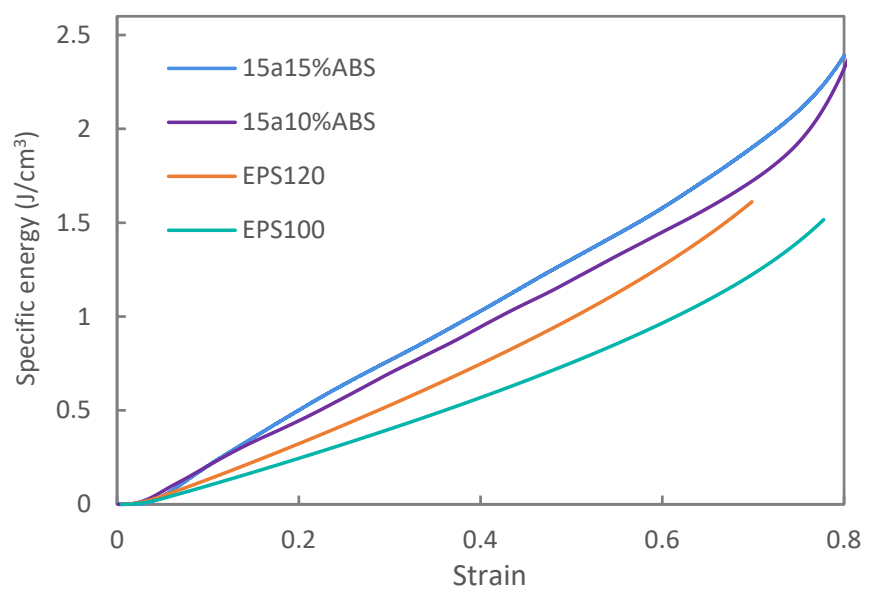

Figure 17. Energy absorption per volume of EPS and ABS.

Fig. 18 shows the comparison plots of the stress-strain curves of PA12 and EPS 100; the plateau stress in the sheet gyroid structure exhibited a horizontal collapse without exceeding the initial peak stress, attaining densification at 70\% strain. In contrast, PS100 exhibited a slope from the beginning from 1.36 to $1.87 \mathrm{MPa}$, attaining densification at $45 \%$ strain. 


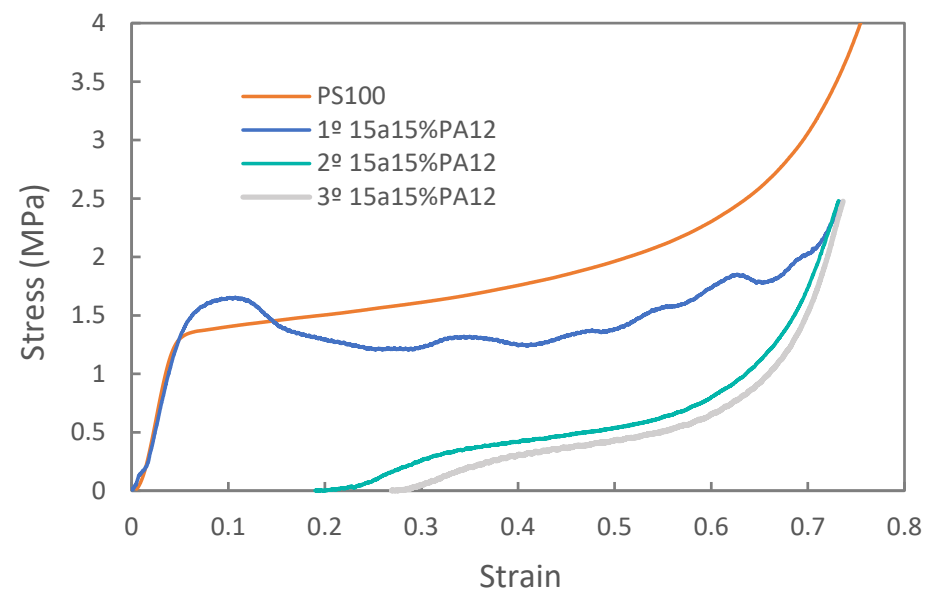

Figure 18. Stress-strain curves of 15a15\%PA12 and EPS100

After densification, EPS remained crushed, losing its ability to absorb more impacts. In contrast, PA12 sheet gyroid maintained its absorbing energy in the two subsequent compression tests. This resulted in EPS100 exhibiting a specific energy absorption of $6.58 \mathrm{~kJ} / \mathrm{kg}$, whereas the PA12 sheet gyroid exhibited $10.36 \mathrm{~kJ} / \mathrm{kg}$ in total. Translated to an application, using PA12 as a substitute of the EPS on helmets can lead to $36 \%$ more impact absorption for the same weight or same protection level but for a $36 \%$ lighter material.

This weight energy absorption ratio can be even bigger considering that a sheet gyroid serves as a structural and crushable member, providing dual benefits for support and impact mitigation and not requiring to rely on further structural elements as EPS does.

The ability of TPU and PA12 sheet gyroids to recover and maintain their absorbing energy where EPS will be crushed after the first impact can be a notable advantage in contact sports where many collisions are produced during a match, or in traffic crashes which often involve successive impacts against cars, pavements, and urban structures. 
One of the main concerns of protective gear, after energy absorption, is comfort, often constrained by the heat-insulating properties of EPS and, in most scenarios, the reason for its disuse 10 . Sheet gyroid structures enable airflow in the $\mathrm{x}, \mathrm{y}$, and $\mathrm{z}$ axes, which can provide a significant improvement for sports or military applications, where helmets are worn for many hours.

As demonstrated, we can leverage these improvements and customize the analyzed variables such as cell size, density, and a large spectrum of material constituent properties for each application; for example, using types of impact zones or vulnerable areas as inputs.

Table 3. Summary of all compression test of sheet gyroids and EPS.

\begin{tabular}{|c|c|c|c|c|c|c|c|c|c|c|}
\hline $\begin{array}{l}\text { Cell } \\
\text { size } \\
(\mathrm{mm})\end{array}$ & $\begin{array}{c}\text { Vol. } \\
\text { Frac. } \\
(\%)\end{array}$ & Mass (g) & $\begin{array}{l}\text { Density } \\
\left(\mathrm{kg} / \mathrm{m}^{3}\right)\end{array}$ & $\begin{array}{c}\text { el. geo } \\
\text { stiff. } \\
\text { (MPa) }\end{array}$ & $\begin{array}{l}\text { Peak } \\
\text { Stress } \\
\text { (MPa) }\end{array}$ & $\begin{array}{c}\text { Drop } \\
\% \\
(\mathrm{MPa})\end{array}$ & $\begin{array}{c}\text { Plateau } \\
\text { S ISO } \\
\text { (MPa) }\end{array}$ & $\begin{array}{l}\text { Peak St. } \\
\text { (MPa/g) }\end{array}$ & $\begin{array}{c}\text { Max } \\
\text { Strain } \\
(\%)\end{array}$ & $\begin{array}{c}\text { Total } \\
\text { Ene. } \\
\text { Ab. } \\
\text { (kJ/kg) }\end{array}$ \\
\hline \multicolumn{11}{|c|}{ SHEET GYROID PLA $\left(1.22 \mathrm{~g} / \mathrm{cm}^{3}\right)$} \\
\hline \multirow{3}{*}{10} & 15 & 23.3 & 186.4 & 86.83 & 2.73 & 0.24 & 2.26 & 0.117 & 0.70 & 8.29 \\
\hline & 20 & 30.7 & 245.6 & 118.68 & 3.97 & 0.29 & 2.90 & 0.129 & 0.67 & 8.96 \\
\hline & 25 & 36.8 & 294.4 & 156.56 & 4.66 & 0.22 & 3.78 & 0.127 & 0.63 & 8.71 \\
\hline \multirow{5}{*}{15} & 10 & 15.8 & 126.4 & 58.87 & 1.37 & 0.38 & 0.89 & 0.087 & 0.73 & 5.71 \\
\hline & 15 & 22.8 & 182.4 & 74.48 & 2.28 & 0.27 & 1.92 & 0.100 & 0.69 & 6.86 \\
\hline & 20 & 31.4 & 251.2 & 111.24 & 3.70 & 0.24 & 3.03 & 0.118 & 0.67 & 8.27 \\
\hline & 25 & 38.6 & 308.8 & 130.62 & 4.93 & 0.28 & 3.74 & 0.128 & 0.63 & 8.11 \\
\hline & 30 & 46.4 & 371.2 & 181.38 & 6.62 & 0.27 & 5.28 & 0.143 & 0.60 & 8.37 \\
\hline \multirow{3}{*}{20} & 15 & 23.6 & 188.8 & 58.46 & 2.58 & 0.36 & 1.65 & 0.109 & 0.70 & 6.53 \\
\hline & 20 & 31.0 & 248.0 & 72.89 & 3.81 & 0.36 & 2.78 & 0.123 & 0.70 & 7.95 \\
\hline & 25 & 40.1 & 320.8 & 112.65 & 5.36 & 0.33 & 3.81 & 0.134 & 0.64 & 8.16 \\
\hline \multicolumn{11}{|c|}{ SHEET GYROID ABS $\left(1.195 \mathrm{~g} / \mathrm{cm}^{3}\right)$} \\
\hline \multirow{4}{*}{15} & 10 & 22.11 & 0.1769 & 85.58 & 2.88 & 0.25 & 2.5 & 0.1301 & 0.68 & 9.38 \\
\hline & 15 & 22.7 & 181.6 & 92.30 & 3.41 & 0.27 & 2.72 & 0.150 & 0.70 & 10.49 \\
\hline & 20 & 25.6 & 204.8 & 93.23 & 3.76 & 0.27 & 2.97 & 0.147 & 0.67 & 9.82 \\
\hline & 25 & 33.1 & 264.8 & 124.95 & 5.07 & 0.42 & 3.05 & 0.153 & 0.66 & 9.34 \\
\hline \multicolumn{11}{|c|}{ SHEET GYROID TPU $\left(0.96 \mathrm{~g} / \mathrm{cm}^{3}\right)$} \\
\hline \multirow{3}{*}{15} & 15 & 22.2 & 177.6 & 0.86 & 0.07 & 0.14 & 0.06 & 0.003 & 0.58 & 0.57 \\
\hline & 20 & 30.7 & 245.6 & 1.24 & 0.18 & 0.13 & 0.18 & 0.006 & 0.56 & 0.96 \\
\hline & 25 & 36.9 & 295.2 & 1.67 & 0.30 & 0.03 & 0.29 & 0.008 & 0.54 & 1.26 \\
\hline
\end{tabular}




\section{SHEET GYROID PA12 $\left(1.02 \mathrm{~g} / \mathrm{cm}^{3}\right)$}

\begin{tabular}{|l|l|l|l|l|l|l|l|l|l|l|}
\hline \multirow{3}{*}{15} & 15 & 17.6 & 140.8 & 35.55 & 1.65 & 0.27 & 1.26 & 0.094 & 0.70 & 10.36 \\
\cline { 2 - 11 } & 20 & 23.7 & 189.6 & 53.24 & 2.56 & 0.15 & 2.29 & 0.108 & 0.66 & 12.44 \\
\cline { 2 - 12 } & 25 & 29.3 & 234.4 & 65.89 & 3.56 & 0.08 & 3.41 & 0.122 & 0.64 & 14.16 \\
\hline
\end{tabular}

EPS
\begin{tabular}{|c|c|c|c|c|c|c|c|c|c|c|}
\hline EPS60 & - & 10.0 & 80.0 & 9.93 & 0.60 & - & 0.73 & 0.060 & 0.55 & 4.69 \\
\hline EPS80 & - & 10.0 & 80.0 & 15.61 & 0.80 & - & 1.07 & 0.080 & 0.50 & 6.09 \\
\hline EPS100 & - & 12.5 & 100.0 & 40.39 & 1.35 & - & 1.62 & 0.108 & 0.45 & 6.58 \\
\hline EPS120 & - & 15.0 & 120.0 & 48.03 & 1.70 & - & 2.13 & 0.113 & 0.40 & 6.23 \\
\hline
\end{tabular}




\section{Conclusion}

In this study, we examined the different variables affecting the mechanical properties and quasistatic absorption performance of sheet gyroids to determine the optimal values for each application and establish a comparison with the currently used materials. First, specimens were designed and manufactured using FDM, changing the structure variables, cell size and volume fraction, for various thermoplastic materials. Subsequently, the specimens were tested using quasi-static compression and their deformation stages photographed. Finally, the recorded experimental results lead to the following conclusions:

The mechanical behavior of materials after adopting the sheet gyroid structure changed by beginning with a linear stress-strain controlled by bending of cell walls, followed by a long collapse plateau associated with the formation of — depending on the material—plastic hinges or brittle crushing, and ending with the opposing walls touching each other and causing densification. Layer collapse was strongly related to the volume fraction; lower volume fractions exhibited a layer-by-layer collapse, while higher volumes collapsed all at once. In addition, the constituent material contributed significantly to the collapse behavior; the four materials tested followed the deformation mechanisms described by Gibson and Ashby for foams: elastomeric, elastic-plastic, and elastic-brittle.

Elastic geometrical stiffness increased linearly at higher volume fractions and smaller cell sizes, where thinner cells favored flexion. PLA was the stiffest, followed closely by ABS, PA12 had approximately half of the slope, and, finally, TPU was the softest.

Additionally, peak and plateau stress increased linearly with higher volume fractions. While peak stress was not directly affected by cell size, the mean stress values or area under the curve exhibited higher values for smaller cells. Additionally, smaller 
cells had a tendency to exhibit lower stress drop percentages, a behavior which was related to the slenderness previously mentioned.

In terms of materials, ABS exhibited the higher peak stress in all volume fractions, followed by PLA, PA12, and TPU. Owing to its brittle and plastic collapse, ABS suffered the highest stress drops, whereas TPU or PA12 exhibited a novel collapse with almost constant stress due to flexible and plastic crushing.

As expected, lower volume fractions led to higher maximum strains, but in some scenarios, materials also contributed significantly; the low collapse stress required to bend the walls of TPU in comparison with the stress required to further compress the material itself caused a higher stress difference.

For most materials, for higher volume fractions and smaller cells, they exhibited higher specific peak stress and energy absorption. In the first scenario, this was presumably because the optimal manufacturing conditions were obtained, and in the second scenario, this was due to the previously mentioned slenderness and failure propagation. This behavior could lead to a more efficient selection of structure volume fractions, saving print time, materials, and energy. ABS exhibited the highest specific peak stress and energy absorption, making it optimal for lightweight, high-strength, single-crash applications. Considering multiple compressions, the ability of PA12 to recover after impact made it the best performer for lightweight, multiple-impact applications.

The comparison of these properties with those of the current material used for lightweight impact absorption, i.e., EPS, demonstrated the capability of sheet gyroid structures to overcome most of its challenges, exhibiting a superior specific energy absorption, ability to withstand various impacts, letting air flow in its $\mathrm{x}, \mathrm{y}$, and $\mathrm{z}$ axes, and being recyclable. In addition to the observation of the effects of variables to their 
mechanical properties, they enable customization of structures for each application. Thus, sheet gyroid structures can be considered as promising alternatives for more comfortable and, in particular, safer protective gear.

\section{Acknowledgements}

The authors disclosed receipt of the following financial support for the research, authorship, and/or publication of this article: This work was supported by the "University of ZaragozaCentro Universitario de la Defensa” joint Research Grant. (Grant number UZCUD2019-TEC04).

\section{7. $\quad$ References}

1. Al-Ketan O, Adel Assad M, Abu Al-Rub RK. Mechanical properties of periodic interpenetrating phase composites with novel architected microstructures. Composite Structures. 2017;176:9-19. doi:10.1016/j.compstruct.2017.05.026

2. Al-Ketan O, Lee D-W, Rowshan R, Abu Al-Rub RK. Functionally graded and multimorphology sheet TPMS lattices: Design, manufacturing, and mechanical properties. Journal of the Mechanical Behavior of Biomedical Materials. 2020;102:103520. doi:10.1016/j.jmbbm.2019.103520

3. Al-Ketan O, Rowshan R, Abu Al-Rub RK. Topology-mechanical property relationship of 3D printed strut, skeletal, and sheet based periodic metallic cellular materials. Additive Manufacturing. 2018;19:167-183. doi:10.1016/j.addma.2017.12.006

4. Andrews EW, Gioux G, Onck P, Gibson LJ. Size effects in ductile cellular solids. Part II: Experimental results. International Journal of Mechanical Sciences. 2001;43(3):701-713. doi:10.1016/S0020-7403(00)00043-6

5. Aremu A.O., Maskery I, Tuck C. A comparative finite element study of cubic unit cells for 
selective laser melting - Self-supporting Unit cells. :1238-1249.

6. van Baar GJC, Ruslin M, van Eijnatten M, Sándor GK, Forouzanfar T, Wolff J. 3D assessment of damaged bicycle helmets and corresponding craniomaxillo-mandibular skull injuries: A feasibility study. Injury. 2017;48(12):2872-2878. doi:10.1016/j.injury.2017.09.031

7. Bobbert FSL, Lietaert K, Eftekhari AA, Pouran B, Ahmadi SM, Weinans H, Zadpoor AA. Additively manufactured metallic porous biomaterials based on minimal surfaces: A unique combination of topological, mechanical, and mass transport properties. Acta Biomaterialia. 2017;53:572-584. doi:10.1016/j.actbio.2017.02.024

8. Chen Z, Xie YM, Wu X, Wang Z, Li Q, Zhou S. On hybrid cellular materials based on triply periodic minimal surfaces with extreme mechanical properties. Materials and Design. 2019;183:108109. doi:10.1016/j.matdes.2019.108109

9. Depreitere B, Van Lierde C, Maene S, Plets C, Sloten J Vander, Van Audekercke R, Van der Perre G, Goffin J. Bicycle-related head injury: A study of 86 cases. Accident Analysis and Prevention. 2004;36(4):561-567. doi:10.1016/S0001-4575(03)00062-9

10. Finnoff JT, Laskowski ER, Altman KL, Diehl NN. Barriers to bicycle helmet use. Pediatrics. 2001;108(1):2-10. doi:10.1542/peds.108.1.e4

11. Fleck NA, Deshpande VS. The Resistance of Clamped Sandwich Beams to Shock Loading. Journal of Applied Mechanics. 2004;71(3):386-401. doi:10.1115/1.1629109

12. Gibson LJ, Ashby MF. Cellular solids: structure and properties. Cambridge university press; 1999.

13. Kapfer SC, Hyde ST, Mecke K, Arns CH, Schröder-Turk GE. Minimal surface scaffold designs for tissue engineering. Biomaterials. 2011;32(29):6875-6882. doi:10.1016/j.biomaterials.2011.06.012 
14. Lee S, Barthelat F, Hutchinson JW, Espinosa HD. Dynamic failure of metallic pyramidal truss core materials - Experiments and modeling. International Journal of Plasticity. 2006;22(11):2118-2145. doi:10.1016/j.ijplas.2006.02.006

15. Li D, Liao W, Dai N, Xie YM. Comparison of mechanical properties and energy absorption of sheet-based and strut-based gyroid cellular structures with graded densities. Materials. 2019;12(13). doi:10.3390/ma12132183

16. Maskery I, Aboulkhair NT, Aremu AO, Tuck CJ, Ashcroft IA. Compressive failure modes and energy absorption in additively manufactured double gyroid lattices. Additive Manufacturing. 2017;16:24-29. doi:10.1016/j.addma.2017.04.003

17. Maskery I, Aboulkhair NT, Aremu AO, Tuck CJ, Ashcroft IA, Wildman RD, Hague RJM. A mechanical property evaluation of graded density Al-Si10-Mg lattice structures manufactured by selective laser melting. Materials Science and Engineering A. 2016;670:264-274. doi:10.1016/j.msea.2016.06.013

18. Mazur M, Leary M, Sun S, Vcelka M, Shidid D, Brandt M. Deformation and failure behaviour of Ti-6Al-4V lattice structures manufactured by selective laser melting (SLM). International Journal of Advanced Manufacturing Technology. 2016;84(5-8):1391-1411. doi:10.1007/s00170-015-7655-4

19. McKown S, Shen Y, Brookes WK, Sutcliffe CJ, Cantwell WJ, Langdon GS, Nurick GN, Theobald MD. The quasi-static and blast loading response of lattice structures. International Journal of Impact Engineering. 2008;35(8):795-810. doi:10.1016/j.ijimpeng.2007.10.005

20. Miralbes R, Ranz D, Pascual FJ, Zouzias D, Maza M. Characterization of additively manufactured triply periodic minimal surface structures under compressive loading. Mechanics of Advanced Materials and Structures. 2020 Nov 5:1-15. doi:10.1080/15376494.2020.1842948

21. Radford DD, Fleck NA, Deshpande VS. The response of clamped sandwich beams 
subjected to shock loading. International Journal of Impact Engineering. 2006;32(6):968-987. doi:10.1016/j.ijimpeng.2004.08.007

22. Scherer MRJ. Double-Gyroid-Structured Functional Materials. Sythesis and Applications. 2013:7-20. doi:10.1007/978-3-319-00354-2

23. Schoen AH. Infinite periodic minimal surfaces without self-intersections, NASA Techn. Rep. D-5541. 1970.

24. Schwarz HA. Gesammelte mathematische abhandlungen. American Mathematical Soc.; 1972.

25. Sélo RRJ, Catchpole-Smith S, Maskery I, Ashcroft I, Tuck C. On the thermal conductivity of AlSi10Mg and lattice structures made by laser powder bed fusion. Additive Manufacturing. 2020;34:101214. doi:10.1016/j.addma.2020.101214

26. Shi X, Liao W, Li P, Zhang C, Liu T, Wang C, Wu J. Comparison of Compression Performance and Energy Absorption of Lattice Structures Fabricated by Selective Laser Melting. Advanced Engineering Materials. 2020;22(11):2000453. doi:10.1002/adem.202000453

27. Simsek U, Arslan T, Kavas B, Gayir CE, Sendur P. Parametric studies on vibration characteristics of triply periodic minimum surface sandwich lattice structures. The International Journal of Advanced Manufacturing Technology. 2020 Oct 7 [accessed 2021 Feb 23]. http://link.springer.com/10.1007/s00170-020-06136-6. doi:10.1007/s00170-020-06136-6

28. Smith M, Guan Z, Cantwell WJ. Finite element modelling of the compressive response of lattice structures manufactured using the selective laser melting technique. International Journal of Mechanical Sciences. 2013;67:28-41. doi:10.1016/j.ijmecsci.2012.12.004

29. Speirs M, Van Hooreweder B, Van Humbeeck J, Kruth JP. Fatigue behaviour of NiTi shape memory alloy scaffolds produced by SLM, a unit cell design comparison. Journal of the Mechanical Behavior of Biomedical Materials. 2017;70:53-59. 
doi:10.1016/j.jmbbm.2017.01.016

30. Sychov MM, Lebedev LA, Dyachenko SV, Nefedova LA. Mechanical properties of energyabsorbing structures with triply periodic minimal surface topology. Acta Astronautica. 2018;150:81-84. doi:10.1016/j.actaastro.2017.12.034

31. Wang P, Li X, Luo S, Nai MLS, Ding J, Wei J. Additively manufactured heterogeneously porous metallic bone with biostructural functions and bone-like mechanical properties. Journal of Materials Science \& Technology. 2021;62:173-179. doi:10.1016/j.jmst.2020.05.056

32. Yan C, Hao L, Hussein A, Raymont D. Evaluations of cellular lattice structures manufactured using selective laser melting. International Journal of Machine Tools and Manufacture. 2012;62:32-38. doi:10.1016/j.ijmachtools.2012.06.002

33. Yan C, Hao L, Hussein A, Young P. Ti-6Al-4V triply periodic minimal surface structures for bone implants fabricated via selective laser melting. Journal of the Mechanical Behavior of Biomedical Materials. 2015;51:61-73. doi:10.1016/j.jmbbm.2015.06.024

34. Yan C, Hao L, Hussein A, Young P, Huang J, Zhu W. Microstructure and mechanical properties of aluminium alloy cellular lattice structures manufactured by direct metal laser sintering. Materials Science and Engineering A. 2015;628:238-246.

doi:10.1016/j.msea.2015.01.063

35. Yan C, Hao L, Hussein A, Young P, Raymont D. Advanced lightweight 316L stainless steel cellular lattice structures fabricated via selective laser melting. Materials and Design. 2014;55:533-541. doi:10.1016/j.matdes.2013.10.027

36. Zhang L, Feih S, Daynes S, Chang S, Wang MY, Wei J, Lu WF. Energy absorption characteristics of metallic triply periodic minimal surface sheet structures under compressive loading. Additive Manufacturing. 2018;23:505-515. doi:10.1016/j.addma.2018.08.007 